\title{
Metoprolol rescues endothelial progenitor cell dysfunction in diabetes
}

Lang Yan ${ }^{E q u a l ~ f i r s t ~ a u t h o r, ~} 1$, Yi-fan Dong Equal first author, 1 , Tao-lin Qing ${ }^{1}$, Ya-ping Deng ${ }^{2}$, Xue Han ${ }^{3}$, Wen-jing Shi ${ }^{1}$, Jin-feng Li , Fang-yuan Gao ${ }^{1}$, Xiao-fang Zhang ${ }^{1}$, Yi-jun Tian ${ }^{1}$, Xiao-yu Dai ${ }^{1}$, Jiang-bo Zhu ${ }^{\text {Corresp., } 1}{ }^{1}$, Ji-kuai Chen ${ }^{\text {Corresp. } 1}$

${ }^{1}$ Department of Health Toxicology, Faculty of Naval Medicine, Second Military Medical University, Shanghai, China

2 Department of Pharmacy, Zhejiang Xiaoshan Hospital, Hangzhou, China

3 Laboratory Animal Center, Hangzhou Medical College, Hangzhou, China

Corresponding Authors: Jiang-bo Zhu, Ji-kuai Chen

Email address: jiangbozhu1@163.com, cjk.smmu@hotmail.com

Added risk portended by diabetes in addition to hypertension has been related to an amplification of endothelial dysfunction. $\beta$-blockers are widely used for cardiovascular diseases and improve the endothelial function compared with a placebo. However, the effect of $\beta$-blockers on the endothelial progenitor cells (EPCS) function in diabetes is still unknown. Five $\beta$-blockers (metoprolol, atenolol, propranolol, bisoprolol, and nebivolol) were tested in EPC functional screening. Metoprolol improved EPC function significantly among the five $\beta$-blockers and was chosen for the in vivo tests in STZ induced diabetic mice. Reactive hyperemia peripheral arterial tonometry (RH-PAT) measurements were performed using the Endo-PAT2000 device in diabetic patients. Metoprolol, but not other $\beta$ blockers, improved EPC function in both tube formation and migration assay. EPC function was significantly decreased in diabetic mice, and metoprolol treatment restored damaged EPC migration capabilities and circulation EPC number. Metoprolol treatment promoted wound healing and stimulated angiogenesis in diabetic mice. Furthermore, metoprolol significantly enhanced eNOS phosphorylation and decreased $\mathrm{O}_{2}{ }^{-}$levels in EPCs of diabetic mice. In clinical trials, the RH-PAT index was significantly higher in metoprolol-treated versus bisoprolol-treated diabetics. Metoprolol could accelerate wound healing in diabetic mice and improve endothelial function in diabetic subjects, which may be mediated in part by improving impaired EPC function. 
1 Metoprolol rescues endothelial progenitor cell dysfunction in 2 diabetes

3

4 Lang Yan ${ }^{1, \dagger}$, Yi-fan Dong ${ }^{1, \dagger}$, Tao-lin Qing ${ }^{1, \dagger}{ }^{\dagger}$, Ya-ping Deng ${ }^{2}$, Xue Han ${ }^{3}$, Wen-jing Shi ${ }^{1}$, Jin-feng Li $^{1}$, Fang-

5 yuan $\mathrm{Gao}^{1}$, Xiao-fang Zhang ${ }^{1}$, Yi-jun Tian ${ }^{1}$, Xiao-yu Dai ${ }^{1}$, Jiang-bo Zhu ${ }^{1}$, Ji-kuai Chen ${ }^{1}$

6

7 Affiliations

8 1. Department of Health Toxicology, Faculty of Naval Medicine, Second Military Medical University, Shanghai

9200433 , China

2. Department of Pharmacy, Zhejiang Xiaoshan Hospital, Hangzhou, Zhejiang, China

3. Laboratory Animal Center, Hangzhou Medical College, Hangzhou, Zhejiang, China

12

\section{Corresponding Author:}

Ji-kuai Chen, Department of Health Toxicology, Second Military Medical University, 800 Xiangyin Road, Shanghai, 200433, China. E-mail: cjk.smmu@hotmail.com Shanghai, 200433, China. E-mail: jiangbozhu1@163.com.

$\dagger$ These authors contributed equally to this work. 


\section{ABSTRACT}

Added risk portended by diabetes in addition to hypertension has been related to an amplification of endothelial dysfunction. $\beta$-blockers are widely used for cardiovascular diseases and improve the endothelial function compared with a placebo. However, the effect of $\beta$-blockers on the endothelial progenitor cells (EPCs) function in diabetes is still unknown. Five $\beta$-blockers (metoprolol, atenolol, propranolol, bisoprolol, and nebivolol) were tested in EPC functional screening. Metoprolol improved EPC function significantly among the five $\beta$-blockers and was chosen for the in vivo tests in STZ induced diabetic mice. Reactive hyperemia peripheral arterial tonometry (RH-PAT) measurements were performed using the Endo-PAT2000 device in diabetic patients. Metoprolol, but not other $\beta$-blockers, improved EPC function in both tube formation and migration assay. EPC function was significantly decreased in diabetic mice, and metoprolol treatment restored damaged

EPC migration capabilities and circulation EPC number. Metoprolol treatment promoted wound healing and stimulated angiogenesis in diabetic mice. Furthermore, metoprolol significantly enhanced eNOS phosphorylation and decreased $\mathrm{O}_{2}^{-}$levels in EPCs of diabetic mice. In clinical trials, the RH-PAT index was significantly higher in metoprolol-treated versus bisoprolol-treated diabetics. Metoprolol could accelerate wound by improving impaired EPC function. 
39

40

41

42

43

44

45

46

47

\section{Introduction}

Hypertension and diabetes mellitus are both well-known cardiovascular risk factors that are often comorbid.

From 2011-2016, 77.1\% of U.S. adults with diagnosed diabetes had high blood pressure (Muntner et al., 2018).

Hypertensive patients with diabetes mellitus were also classified as having very high cardiovascular risk by the

European Society of Hypertension/European Society of Cardiology Guidelines (Williams et al., 2018).

Increasing evidence has demonstrated that the added risk portended by diabetes in addition to hypertension might

be related to the amplification of endothelial dysfunction (Cleland et al., 2000). Furthermore, hypertension and diabetes mellitus have been identified as major independent predictors for impaired function of endothelial progenitor cells (EPCs) (Vasa et al., 2001). Thus, the possible impact on endothelial function should be taken into consideration when choosing an antihypertensive agent for diabetic patients with hypertension.

$\beta$-blockers are widely used for cardiovascular diseases, such as cardiac arrhythmias, arterial hypertension, and angina pectoris (Cruickshank, 2010; Frishman, 2003). The primary mechanism of $\beta$-blockers is in their capacity to block the $\beta$-adrenoceptors. However, several earlier observations indicated that part of the therapeutic effects shown by propranolol and metoprolol was associated with the antioxidant properties (Gomes et al., 2006;

Vanhoutte \& Gao, 2013). Further studies indicated that nebivolol treatment preserved endothelial-dependent vasodilatation and EPC mobilization, which were explained by the inhibition of NADPH oxidase activity and superoxide production in endothelial cells (Mason et al., 2009; Peller et al., 2015; Sorrentino et al., 2011). However, the different role of $\beta$-blockers on EPC function in diabetes with hypertension has yet to be determined.

We hypothesize that, under a diabetic state, the use of a $\beta$-blocker to reduce superoxide production maintains better EPC function than a $\beta$-blocker without that effect. To test this hypothesis, we compared the effects of five 
60

$\beta$-blockers (propranolol, metoprolol, atenolol, bisoprolol, and nebivolol) on endothelial cell function and EPC function. Moreover, we examined the effect of metoprolol on high glucose-induced EPC dysfunction, wound healing in mice, and endothelial function in diabetic patients.

\section{Materials and methods}

Reagents, cell culture, and treatment

Metoprolol, atenolol, propranolol, bisoprolol, nebivolol and D-glucose were purchased from Sigma-Aldrich (St. Louis, MO). Metoprolol $(0.3 \mu \mathrm{M})$, atenolol $(3 \mu \mathrm{M})$, propranolol $(0.3 \mu \mathrm{M})$, bisoprolol $(0.3 \mu \mathrm{M})$, nebivolol $(3$ $\mathrm{nM}$ ) were dissolved in DMSO for cell experiments (chose the highest blood drug concentrations based on their pharmacokinetic parameters) (Eddington et al., 2000; Kamali et al., 1997; Le Coz et al., 1991; Spahn et al., 1984). Metoprolol was dissolved in carboxyl methyl cellulose (CMC)-Na (0.5\%) for animal experiments. HUVECs were obtained from Fuheng Bio (FH1122, Fuheng Cell Center, Shanghai, China) and cultured in DMEM medium (HyClone, Logan, Utah) containing 4.5 mM D-glucose supplemented with 10\% FBS, $100 \mathrm{U} / \mathrm{ml}$ penicillin, and $100 \mathrm{mg} / \mathrm{ml}$ of streptomycin. Cells in the high glucose group were incubated with a $33 \mathrm{mM} \mathrm{D-}$ glucose medium.

\section{Determination of HUVEC and EPC function}

Circulating EPCs were characterized using flow cytometry as cells that co-expressed Flk-1 and Sca-1 (BD Pharmingen, San Diego, CA). Mouse bone marrow (BM) EPCs were isolated, cultured and identified according to our previously established method (Chen et al., 2013). Migration assay and tube formation assay were used to evaluate HUVEC and BM-EPC functions. Migration was assayed by a filter membrane technique. Briefly, 5 $\times 10^{4}$ cells were placed in the upper chamber of a 24-well Transwell plate (Corning Transwell, Lowell, MA) 
with an $8-\mu \mathrm{m}$ polycarbonate membrane. VEGF (50 $\mathrm{ng} / \mathrm{ml}$, Sigma-Aldrich) was added to the culture medium

placed in the lower chamber. After incubating at $37^{\circ} \mathrm{C}$ for 24 hours, the upper side of the filter was gently scraped with a cotton swab to remove non-migrating cells. After being stained with Hoechst 33258 (5 $\mu \mathrm{M}$, Molecular Probes), cells that migrated into the lower chamber were determined by counting the stained nuclei using an Olympus IX71 fluorescence microscope (Olympus, Japan).

The angiogenic capacity was determined by the Matrigel tube formation assay ( $\mathrm{Li}$ et al., 2016). Briefly, $2 \times$ $10^{4}$ HUVECs or $4 \times 10^{4}$ BM-EPCs were added into each well of a 96-well Matrigel (BD Biosciences, Bedford, MA) pre-coated ( $50 \mu \mathrm{l} /$ well) plate and incubated for $3 \mathrm{~h}$. The number of tubes was examined using an Olympus IX71 fluorescence microscope (Olympus, Japan) and ImageJ software (1.48v, NIH, USA).

\section{Determination of ROS generation by flow cytometry and fluorescent microscopy}

Dihydroethidium (DHE) (Invitrogen, Carlsbad, CA) assay is used to determine intracellular $\mathrm{O}_{2}{ }^{-}$levels. BM-

EPCs were incubated with DHE $\left(10^{-6} \mathrm{~mol} / \mathrm{L}\right)$ for $30 \mathrm{~min}$ in a cell incubator. The fluorescence intensity for 10,000 events was measured using FACS (fluorescence activated cell sorting, BD). Culture plates were read at 518/605

$\mathrm{nm}$ in a SpectraMax M2e microplate reader (Molecular Devices, Sunnyvale, CA) and images were captured under the Olympus IX71 fluorescence microscope (Olympus, Japan).

\section{Animal studies}

Male C57BL/6 mice (18-20 g) were purchased from the SIPPR/BK Lab Animal Ltd. (Shanghai, China), housed under SPF conditions with free access to food and water (temperature: $21 \pm 2{ }^{\circ} \mathrm{C}$ and lighting: 8:0020:00). Animal protocols were approved by Committee on Ethics of Biomedicine of Second Military Medical University (IACUC-2017324). All mice were treated humanely and with efforts to minimize suffering. To induce death with a minimum of pain and distress, all mice were euthanized by displacement of air with $100 \%$ carbon 
102

103

104

105

106

107

108

109

110

111

112

113

114

115

116

117

118

119

120

121

122

dioxide to collected tissue samples for further analyses. There were no surviving animals at the end of study.

Diabetes mellitus was induced in male C57BL/6 mice by streptozotocin (STZ; Amresco, Solon, Ohio)

treatment. STZ was dissolved in $0.1 \mathrm{mM}$ sodium citrate buffer $(\mathrm{pH} 4.5)$ and $60 \mathrm{mg} / \mathrm{kg}$ body weight was

administered daily by intraperitoneal injection for 5 days (administration volume: $10 \mathrm{ml} / \mathrm{kg}$; administration

concentration: $6 \mathrm{mg} / \mathrm{ml}$ ). Mice whole blood was obtained from the tail veins on day 20. Blood glucose levels

were measured using a blood glucose monitoring system (Sinocare, Changsha, China). Mice with fasting blood

glucose levels over $13.8 \mathrm{mM}$ were defined as diabetic mice. Control mice were treated with citrate buffer $(\mathrm{n}=8)$.

STZ-induced diabetic mice (mentioned above) were randomly divided into two groups, each with $0.5 \%$ CMC-

$\mathrm{Na}(\mathrm{n}=8)$ or metoprolol (Sigma-Aldrich, $100 \mathrm{mg} / \mathrm{kg}$, intragastric administration $(\mathrm{ig}), \mathrm{n}=8) 14$ days of treatment.

The control mice received vehicle only. On day 34, mice were used for wound closure experiments or EPC isolation.

\section{Western blot analysis}

Samples of approximately $20 \mu \mathrm{g}$ were run on $10 \%$ SDS-PAGE. The proteins were then electro-transferred to PVDF membranes (Millipore). The membranes were incubated in blocking buffer (Beyotime Biotechnology, China) for $4 \mathrm{~h}$ at room temperature. The blots were then incubated overnight at $4{ }^{\circ} \mathrm{C}$ with primary antibodies for eNOS, p-eNOS (Ser-1177) and $\beta$-Actin (Cell Signaling Technology, Danvers, Mass), and then incubated with HRP-conjugated secondary antibody (1:1000, Promega) (1:5,000; Cell Signaling Technology, Danvers, Mass) for 1 hour at $25^{\circ} \mathrm{C}$. The Luminescence signal was obtained using GE Amersham AI600 (GE Healthcare), and the bands were quantified by Image J software (NIH, USA).

\section{Measurement of wound closure and angiogenesis}

Mice were anesthetized with isoflurane (3\%), and the back was hairless and wiped 3 times with betaine and 
123

124

125

126

127

128

129

130

131

132

133

134

135

136

137

138

139

140

141

142

143

$75 \%$ ethanol before surgery. A $6 \mathrm{~mm}$ round wound was created with a biopsy punch. Each wound area was

tracked every 2 days with a transparent, biocompatible transparent dressing (Johnson and Johnson, Arlington,

Texas, USA) for 12 days to measure wound closure rate. The traces were digitized and the area was calculated

using Image J software.

Lesions were obtained on days 3, 6, and 9 after wounding. Samples were fixed in paraformaldehyde before wax, then embedded in paraffin and sectioned at $5-\mu \mathrm{m}$ intervals. Immerse the slide in a $3 \%$ hydrogen peroxide/methanol bath for 20 minutes and rinse with distilled water to block endogenous peroxidase. After treatment with normal rabbit serum for 30 minutes (Beyotime, Shanghai), the slides were incubated with antiCD 31 antibodies (1:50; BD) for 60 minutes at room temperature and then incubated with Vectastain Elite ABC reagent (Vector Lab) 30 minutes, Nova Red (Vector Lab) 15 minutes. Slides were counterstained with hematoxylin (Beyotime, Shanghai) for 10 seconds, differentiated in a $1 \%$ glacial acetic acid aqueous solution, and rinsed in running tap water. Capillaries were recognized as tubular structures positive for CD31, and capillary density in the healing wounds was quantified.

\section{Endothelial function testing in patients}

Twelve healthy individuals (6 Male, $49 \pm 7.5$ years, BMI $22 \pm 1.3 \mathrm{~kg} / \mathrm{m}^{2}$ ) and 43 Type 2 diabetic patients (10 onset diabetic patients: 5 Male, $52.7 \pm 7.6$ years, BMI 26.3 \pm 4.5 ; 19 treated with metoprolol: 9 Male, $66 \pm 10.6$ years, BMI $25 \pm 2.9 \mathrm{~kg} / \mathrm{m}^{2} ; 14$ treated with bisoprolol: 2 Male, $53 \pm 12.3$ years, BMI $28 \pm 4.7 \mathrm{~kg} / \mathrm{m}^{2}$ ) were recruited. All had normal tests for hematologic, renal and liver function. None of the participants with type 2 diabetes had suffered from hypoglycemia in the preceding week before the study. None of the subjects practiced vigorous exercise. Treatments used in this study were metoprolol $100 \mathrm{mg}$ twice daily or bisoprolol $5 \mathrm{mg}$ once daily. All the participants were aware of this study and had provided written informed consent forms; this study 
144

145

146

147

148

149

150

151

152

153

154

155

156

157

158

159

160

161

162

163

164

was approved by the Committee on Ethics of Biomedicine of Second Military Medical University (SMMU2017324).

The testing of endothelial function was performed as described previously (Axtell et al., 2010). Subjects were asked to quit smoking and refrain from drinking alcohol or caffeinated beverages for 12 hours. During the test, the subject was seated in a particularly comfortable chair with both hands at the height of the heart. The EndoPAT 2000 device (Itamar Medical Ltd, Caesarea, Israel) was used to obtain inter-finger pulsograms to record finger arterial pulse wave amplitude (PWA). Place a pneumatic probe on the index finger of each hand to record peripheral arterial tension (PAT). After a 20-minute equilibration period (temperature range $21-24{ }^{\circ} \mathrm{C}$ ), baseline levels were measured for 5 minutes at rest and then for 5 minutes with one arm occluded. Obstruction is caused by inflating the pressure cuff of the upper arm to $50 \mathrm{mmHg}$ above systolic blood pressure and then releasing it to induce reactive (blood flow mediated) congestion. Another un-occluded hand is used as a reference to correct potential systemic changes. The post-obstructive PWA was measured starting $90 \mathrm{~s}$ after cuff deflation, for 210

s. Endothelial function was calculated as the ratio of the average post-occlusion PWA to the average 5-minute baseline PWA and was corrected for systemic changes and baseline signal amplitude. The signal is analyzed using a computer-automatic algorithm to eliminate differences within and between observers.

\section{Statistical analysis}

Data are shown as the mean \pm S.E.M. The statistical significance of differences between groups was obtained by the unpaired Student's t-test or 1-way ANOVA with Newman-Keuls multiple comparison test in GraphPad Pro7.0 (GraphPad, San Diego, CA). Comparisons between multiple time points were analyzed by repeatedmeasurements analysis of variance with Bonferroni post-tests. Differences were considered to be significant at $p<0.05$. 


\section{Results}

Comparative effects of different $\beta$-blockers on tube formation and migration capacities in HUVECs and BM-

EPCs

Five $\beta$-blockers (metoprolol, atenolol, propranolol, bisoprolol, and nebivolol) were included in this study.

Propranolol and metoprolol increased tube formation capacity by 91 and $39 \%$ in HUVECs, respectively,

formation and migration capacities were not observed to increase significantly with the induction of atenolol or

BM-EPCs, while propranolol increased the migration capacity (Figure 1AA and 1BB). Thus, metoprolol was shown to enhance tube formation and migration capacities in both HUVECs and BM-EPCs.

\section{Metoprolol improved BM-EPC function in diabetic mice}

We also tested the effects of metoprolol on the capacities of tube formation and migration in BM-EPCs under a high glucose condition in vitro or in vivo. Tube formation and migration capacity were significantly reduced in the high glucose group compared with the control (Figure 2A-2H). Treatment with metoprolol significantly improved BM-EPC function, compared with the high glucose treatment (Figure 2A-2H).

Fifteen days after 5 days of treatment with STZ, the blood glucose levels of STZ-induced diabetic mice were showed significantly reduced cell migration capacity. Compared with untreated diabetic mice, metoprolol 
186

treatment significantly improved the tube formation ability and the migration ability of STZ-induced diabetic mice (Figure 2I-2P). Similarly, the percentage of circulating EPC was significantly reduced in STZ-induced diabetic mice compared with that in the control group. Metoprolol treatment prevented this reduction in EPC in diabetic mice (Figure 2Q-2T).

Metoprolol reduced superoxide generation and increased phospho-eNOS levels in BM-EPCs from diabetic

mice

As shown in Figure 3A-3D, superoxide levels in the high glucose-loaded BM-EPCs were significantly higher than those in the control. Metoprolol significantly reduced superoxide levels in BM-EPCs under the high glucose condition. Similarly, the enhanced superoxide anion production in BM-EPCs of STZ-induced diabetic mice was also inhibited by metoprolol (Figure 3E-3H). The effects of five $\beta$-blockers on the high-glucoseinduced generation of reactive oxygen species (ROS) were also compared in HUVECs (Figure 4). Both the metoprolol and bisoprolol groups showed significantly lower $\mathrm{O}_{2}^{-}$levels compared to the high glucose group. Treatment with propranolol, atenolol, or nebivolol alone had no obvious effect on $\mathrm{O}_{2}{ }^{-}$production under the highglucose condition in HUVECs.

Western blot analysis showed no differences in total eNOS protein expression in BM-EPCs among the groups (Figure 3I and 3J). However, compared with the control group, the amount of phosphorylated eNOS relative to total eNOS was significantly reduced in BM-EPCs from STZ-induced diabetic mice. Metoprolol treatment significantly reversed the decrease in BM-EPCs from diabetic mice (Figure 3I and 3J).

\section{Metoprolol accelerated wound closure and angiogenesis in diabetic mice}

Full thickness excisional skin wounds were generated on the backs of diabetic mice. These mice were treated with Metoprolol or vehicle, and examined every other day until day 12 (Figure 5A). On day 12, it was noted that 
207 208 209

wound closure was significantly delayed in diabetic mice than in control mice (Figure 5A-5V). However, the rate of wound closure was higher in the diabetic mice treated with metoprolol than in the untreated diabetic mice (Figure 5A-5V).

As angiogenesis plays a pivotal role in wound healing, we investigated whether the accelerated wound healing by metoprolol was associated with increased angiogenesis in wound tissues. At days 3, 6, and 9 after wounding, the number of microvessels was significantly smaller in wound beds of diabetic mice than in the controls $(p<0.05$, Figure 6A-6S). Compared with untreated diabetic mice, metoprolol treatment significantly increased capillary density in diabetic mice on days 6 and 9 (Figure 6A-6S); metoprolol did not increase capillary formation on day 3 .

\section{Microvascular endothelial function}

RH-PAT is a non-invasive technique that measures peripheral microvascular endothelial function by measuring changes in digital pulse volume during reactive hyperemia (Hamburg et al., 2008). The RH-PAT indices in onset diabetes patients were lower compared to those in the control subjects ( $1.6 \pm 0.14$ vs. $2.4 \pm 0.18$, $p<0.01$; Figure 7A, B). RH-PAT index was higher in metoprolol-treated patients compared with that in onset diabetic patients $(2.3 \pm 0.15$ vs. $1.6 \pm 0.14, p<0.01$; Figure $7 \mathrm{~A}, \mathrm{~B})$. There was no significant difference in the RH-PAT indices of onset diabetic patients and bisoprolol-treated patients. The characteristics of the patient population can be found in Table 1.

\section{Discussion}

The present study demonstrated that metoprolol, a selective $\beta_{1}$ receptor blocker, improved EPC function, accelerated angiogenesis, decreased the superoxide anion and increased the phosphorylation of eNOS in EPCs 
228

229

230

231

232

233

234

235

236

237

238

239

240

241

242

243

244

245

246

247

248

from diabetes. A validation study demonstrated that endothelial function was improved in diabetic patients

treated with metoprolol. The results support the notion that the beneficial effects of metoprolol on endothelial and EPC function may be related to phosphorylation of eNOS and scavenging of superoxide anions.

These findings are important because most patients with diabetes and hypertension receive $\beta$-blocker treatment. Previous studies have shown that beta-blockers (such as propranolol) negatively regulate angiogenesis in ischemic models, such as hindlimb ischemia (7) and oxygen-induced retinopathy (18, 23). However, the issue remains controversial. Other studies have demonstrated that metoprolol and bisoprolol displayed proangiogenic activity in a mouse aortic ring model, which is independent of their ability to antagonize catecholamine action (Cheng et al., 2014; Stati et al., 2014). The beneficial effects of nebivolol beyond conventional $\beta$-blockers were also demonstrated in experimental models of post-myocardial infarction (Cheng et al., 2014; Stati et al., 2014).

On the other hand, several reports were consistent with our findings, showing that metoprolol therapy improved endothelial function in patients with cardiac syndrome X (Majidinia et al., 2016) and increased the EPC proliferation in an acute myocardial infarction animal model (Stati et al., 2014). In this study, metoprolol significantly promoted angiogenesis both in vitro (cultured HUVECs and EPCs) and in vivo (wound healing in mice). Antihypertensive drugs and diabetic drugs are often combined in clinical practice. Yu et al. reported that metformin could also improve BM-EPC functions in STZ-induced diabetic mice. Dei et al. found that Vildagliptin, but not glibenclamide, increases circulating endothelial progenitor cell number in patients with type 2 diabetes. The combined impact of beta blockers and diabetic drugs in BM-EPCs function is also worth further study.

Both type 1 and type 2 diabetic patients displayed fewer circulating EPCs and had impaired EPC function compared to the matched healthy subjects (De Vriese et al., 2000). Increased oxidative stress along with a 
249

250

251

252

253

254

255

256

257

258

259

260

261

262

263

264

265

266

267

268

269

subsequent decrease in eNOS phosphorylation contributes to EPC dysfunction in diabetes (Kolluru et al., 2012).

$\beta$-blockers have been mainly used based on their capacity to block the $\beta$-adrenoceptors (Gomes et al., 2006).

However, part of the beneficial cardiovascular effects from $\beta$-blockers has been considered to be associated with

the antioxidant properties (Haas et al., 2003). Gomes et al. showed that $\beta$-blockers (atenolol, labetalol, metoprolol, and propranolol et al.) are good ROS and/or RNS scavengers, which may be useful in preventing

the oxidative damages (Gomes et al., 2006). In the present study, the concentration of superoxide anion in the diabetic model was markedly reduced by metoprolol. Metoprolol significantly increased HG-induced eNOS dephosphorylation in EPCs. These results suggest that the effects of metoprolol on improving EPC function might be associated with the reduction of ROS generation and an increase in eNOS phosphorylation in diabetes or induced by HG.

The RH-PAT index calculated using the PAT signal is applied to a parameter of endothelial function. A low RH-PAT index is used to diagnose a patient with endothelial dysfunction (Bonetti et al., 2004). Thus, PAT is considered to be a useful, noninvasive examination for the prediction of cardiovascular events (Rubinshtein et al., 2010). Endothelial dysfunction, as measured by RH-PAT, was also present in diabetic patients (Pareyn et al., 2013). In this study, we compared the effects of chronic therapy with metoprolol and bisoprolol in diabetic patients. The average RH-PAT index was significantly higher in diabetic patients treated with metoprolol compared with that in patients treated with bisoprolol. This effect on endothelial function is predicted to be an intrinsic property of metoprolol. Therefore, conceivably, the beneficial effects of metoprolol in patients with hypertension and diabetes may be due to its preservation of normal endothelial function. However, age-related and gender-related differences in endothelial dysfunction should be considered in this study. Compared with men, endothelial dysfunction occurs late in women (Juonala et al., 2008). In our study, younger age and all-male 
270

271

272

273

274

275

276

277

278

279

280

281

\section{Acknowledgements}

283 Not applicable for this section.

\section{Funding}

285

\section{Conclusions}

gender may also partly account for the higher RH-PAT indexes in the control group.

This study had several limitations. The first is due to the relatively small sample size. There is a possibility that a significant difference in the RH-PAT index among different $\beta$-blockers may be demonstrated with a larger number of subjects. Second, except for metoprolol, the effects of other $\beta$-blockers on endothelial function under diabetic conditions need further detailed experiments. Third, the structure and function of the anti-oxidation effect from treatment with $\beta$-blockers also need further detailed experimentation.

Our work demonstrated that metoprolol could improve EPC function that is damaged by HG or in STZ-

induced diabetic mice, accelerate wound healing in diabetic mice, and maintain microvascular endothelial function in diabetic patients. These results suggest a beneficial effect of metoprolol in the treatment of patients with diabetes mellitus combined with hypertension.

\footnotetext{
This work was supported by the grant from National Natural Science Foundation of China (81703627,
} 81872660,81803643 , and 31900381), the key project of food safety of the Science and Technology Ministry of China (2017YFC1600204) and the Natural Science Foundation of Zhejiang (Grant No. LGJ18H310002). 
288

289

290

291

292

293

294

295

296

297

298

299

300

301

302

303

304

305

306

307

308

309

310

311

312

313

314

315

316

317

318

319

320

321

322

323

324

325

326

327

328

\section{References:}

Axtell, A.L., Gomari, F.A., and Cooke, J.P. 2010. Assessing endothelial vasodilator function with the EndoPAT 2000. J Vis Exp. 10.3791/2167

Bonetti, P.O., Pumper, G.M., Higano, S.T., Holmes, D.J., Kuvin, J.T., and Lerman, A. 2004. Noninvasive identification of patients with early coronary atherosclerosis by assessment of digital reactive hyperemia. JOURNAL OF THE AMERICAN COLLEGE OF CARDIOLOGY 44:2137-2141. 10.1016/j.jacc.2004.08.062

Chen, J.K., Deng, Y.P., Jiang, G.J., Liu, Y.Z., Zhao, T., and Shen, F.M. 2013. Establishment of tube formation assay of bone marrow-derived endothelial progenitor cells. CNS Neuroscience \& Therapeutics 19:533-535. $10.1111 / \mathrm{cns} .12102$

Cheng, K., Wei, M.Q., Jia, G.L., Wang, H.C., Luan, R.H., Guo, W.Y., Li, W.J., Zong, X.J., and Zhou, X. 2014. Effects of metoprolol and small intestine RNA on marrow-derived endothelial progenitor cells applied for autograft transplantation in heart disease. Eur Rev Med Pharmacol Sci 18:1666-1673.

Cleland, S.J., Petrie, J.R., Small, M., Elliott, H.L., and Connell, J.M. 2000. Insulin action is associated with endothelial function in hypertension and type 2 diabetes. HYPERTENSION 35:507-511.

Cruickshank, J.M. 2010. Beta blockers in hypertension. LANCET 376:415, 415-416. 10.1016/S01406736(10)61217-2

De Vriese, A.S., Verbeuren, T.J., Van de Voorde, J., Lameire, N.H., and Vanhoutte, P.M. 2000. Endothelial dysfunction in diabetes. Br J Pharmacol 130:963-974. 10.1038/sj.bjp.0703393

Eddington, N.D., Rekhi, G.S., Lesko, L.J., and Augsburger, L.L. 2000. Scale-up effects on dissolution and bioavailability of propranolol hydrochloride and metoprolol tartrate tablet formulations. AAPS PHARMSCITECH 1:E14. 10.1208/pt010214

Frishman, W.H. 2003. Cardiology patient page. Beta-adrenergic blockers. CIRCULATION 107:e117-e119. 10.1161/01.CIR.0000070983.15903.A2

Gomes, A., Costa, D., Lima, J.L., and Fernandes, E. 2006. Antioxidant activity of beta-blockers: an effect mediated by scavenging reactive oxygen and nitrogen species? Bioorg Med Chem 14:4568-4577. 10.1016/j.bmc.2006.02.023

Haas, S.J., Vos, T., Gilbert, R.E., and Krum, H. 2003. Are beta-blockers as efficacious in patients with diabetes mellitus as in patients without diabetes mellitus who have chronic heart failure? A meta-analysis of largescale clinical trials. AMERICAN HEART JOURNAL 146:848-853. 10.1016/S0002-8703(03)00403-4

Hamburg, N.M., Keyes, M.J., Larson, M.G., Vasan, R.S., Schnabel, R., Pryde, M.M., Mitchell, G.F., Sheffy, J., Vita, J.A., and Benjamin, E.J. 2008. Cross-sectional relations of digital vascular function to cardiovascular risk factors in the Framingham Heart Study. CIRCULATION 117:2467-2474. 10.1161/CIRCULATIONAHA.107.748574

Juonala, M., Kahonen, M., Laitinen, T., Hutri-Kahonen, N., Jokinen, E., Taittonen, L., Pietikainen, M., Helenius, H., Viikari, J.S., and Raitakari, O.T. 2008. Effect of age and sex on carotid intima-media thickness, elasticity and brachial endothelial function in healthy adults: the cardiovascular risk in Young Finns Study. EUROPEAN HEART JOURNAL 29:1198-1206. 10.1093/eurheartj/ehm556

Kamali, F., Howes, A., Thomas, S.H., Ford, G.A., and Snoeck, E. 1997. A pharmacokinetic and pharmacodynamic interaction study between nebivolol and the H2-receptor antagonists cimetidine and ranitidine. Br J Clin Pharmacol 43:201-204. 10.1046/j.1365-2125.1997.54212.x

Peer) reviewing PDF | (2020:03:46982:1:1:NEW 8 May 2020) 
329

330

331

332

333

334

335

336

337

338

339

340

341

342

343

344

345

346

347

348

349

350

351

352

353

354

355

356

357

358

359

360

361

362

363

364

365

366

367

368

369

Kolluru, G.K., Bir, S.C., and Kevil, C.G. 2012. Endothelial dysfunction and diabetes: effects on angiogenesis, vascular remodeling, and wound healing. Int J Vasc Med 2012:918267. 10.1155/2012/918267

Le Coz, F., Sauleman, P., Poirier, J.M., Cuche, J.L., Midavaine, M., Rames, A., Lecocq, B., and Jaillon, P. 1991. Oral pharmacokinetics of bisoprolol in resting and exercising healthy volunteers. J Cardiovasc Pharmacol 18:28-34. 10.1097/00005344-199107000-00005

Li, Z.P., Xin, R.J., Yang, H., Jiang, G.J., Deng, Y.P., Li, D.J., and Shen, F.M. 2016. Diazoxide accelerates wound healing by improving EPC function. Front Biosci (Landmark Ed) 21:1039-1051.

Majidinia, M., Rasmi, Y., Khadem, A.M., Seyed-Mohammadzad, M., Saboory, E., and Shirpoor, A. 2016. Metoprolol Improves Endothelial Function in Patients with Cardiac Syndrome X. Iranian Journal of Pharmaceutical Research 15:561-566.

Mason, R.P., Kubant, R., Jacob, R.F., Malinski, P., Huang, X., Louka, F.R., Borowiec, J., Mizuno, Y., and Malinski, T. 2009. Loss of arterial and renal nitric oxide bioavailability in hypertensive rats with diabetes: effect of beta-blockers. AMERICAN JOURNAL OF HYPERTENSION 22:1160-1166. 10.1038/ajh.2009.163

Muntner, P., Whelton, P.K., Woodward, M., and Carey, R.M. 2018. A Comparison of the 2017 American College of Cardiology/American Heart Association Blood Pressure Guideline and the 2017 American Diabetes Association Diabetes and Hypertension Position Statement for U.S. Adults With Diabetes. DIABETES CARE 41:2322-2329. 10.2337/dc18-1307

Pareyn, A., Allegaert, K., Asscherickx, W., Peirsman, E., Verhamme, P., and Casteels, K. 2013. Impaired endothelial function in female adolescents with type 1 diabetes measured by peripheral artery tonometry. EUROPEAN JOURNAL OF PEDIATRICS 172:1017-1022. 10.1007/s00431-013-1988-5

Peller, M., Ozieranski, K., Balsam, P., Grabowski, M., Filipiak, K.J., and Opolski, G. 2015. Influence of betablockers on endothelial function: A meta-analysis of randomized controlled trials. Cardiology Journal 22:708-716. 10.5603/CJ.a2015.0042

Rubinshtein, R., Kuvin, J.T., Soffler, M., Lennon, R.J., Lavi, S., Nelson, R.E., Pumper, G.M., Lerman, L.O., and Lerman, A. 2010. Assessment of endothelial function by non-invasive peripheral arterial tonometry predicts late cardiovascular adverse events. EUROPEAN HEART JOURNAL 31:1142-1148. 10.1093/eurheartj/ehq010

Sorrentino, S.A., Doerries, C., Manes, C., Speer, T., Dessy, C., Lobysheva, I., Mohmand, W., Akbar, R., Bahlmann, F., Besler, C., Schaefer, A., Hilfiker-Kleiner, D., Luscher, T.F., Balligand, J.L., Drexler, H., and Landmesser, U. 2011. Nebivolol exerts beneficial effects on endothelial function, early endothelial progenitor cells, myocardial neovascularization, and left ventricular dysfunction early after myocardial infarction beyond conventional beta1-blockade. JOURNAL OF THE AMERICAN COLLEGE OF CARDIOLOGY 57:601-611. 10.1016/j.jacc.2010.09.037

Spahn, H., Kirch, W., Mutschler, E., Ohnhaus, E.E., Kitteringham, N.R., Logering, H.J., and Paar, D. 1984. Pharmacokinetic and pharmacodynamic interactions between phenprocoumon and atenolol or metoprolol. Br J Clin Pharmacol 17 Suppl 1:97S-102S. 10.1111/j.1365-2125.1984.tb02439.x

Stati, T., Musumeci, M., Maccari, S., Massimi, A., Corritore, E., Strimpakos, G., Pelosi, E., Catalano, L., and Marano, G. 2014. beta-Blockers promote angiogenesis in the mouse aortic ring assay. $J$ Cardiovasc Pharmacol 64:21-27. 10.1097/FJC.0000000000000085

Vanhoutte, P.M., and Gao, Y. 2013. Beta blockers, nitric oxide, and cardiovascular disease. CURRENT OPINION IN PHARMACOLOGY 13:265-273. 10.1016/j.coph.2012.12.002 
370

371

372

373

Vasa, M., Fichtlscherer, S., Aicher, A., Adler, K., Urbich, C., Martin, H., Zeiher, A.M., and Dimmeler, S. 2001. Number and migratory activity of circulating endothelial progenitor cells inversely correlate with risk factors for coronary artery disease. CIRCULATION RESEARCH 89:E1-E7.

Williams, B., Mancia, G., Spiering, W., Agabiti, R.E., Azizi, M., Burnier, M., Clement, D., Coca, A., De Simone, G., Dominiczak, A., Kahan, T., Mahfoud, F., Redon, J., Ruilope, L., Zanchetti, A., Kerins, M., Kjeldsen, S., Kreutz, R., Laurent, S., Lip, G., McManus, R., Narkiewicz, K., Ruschitzka, F., Schmieder, R., Shlyakhto, E., Tsioufis, K., Aboyans, V., and Desormais, I. 2018. 2018 Practice Guidelines for the management of arterial hypertension of the European Society of Cardiology and the European Society of Hypertension. Blood Press 27:314-340. 10.1080/08037051.2018.1527177 
380

381

382

383

384

385

386

387

388

389

390

391

392

393

394

395

396

397

398

399

400

\section{Figure legends}

Figure 1: Effects of five $\beta$-blockers on HUVECs and EPCs tube formation and migration. HUVECs or EPCs were incubated with PRO (propranolol, $0.3 \mu \mathrm{M}$ ), ATE (atenolol, $3 \mu \mathrm{M}$ ), MET (metoprolol, $0.3 \mu \mathrm{M}$ ), BIS (bisoprolol, $0.3 \mu \mathrm{M}$ ), NEB (nebivolol, $3 \mathrm{nM}$ ), or control for 24 hours and then tested. (A) Typical HUVECs tube formation and migration. (B) Quantitative evaluation of the tube numbers and their numbers of migrated HUVECs from (A). (C) Quantitative evaluation of the tube numbers and the numbers of migrated EPCs. Scale bar: $50 \mu \mathrm{m} . \mathrm{n}=6$. Data represent mean \pm SEM. ${ }^{*}, p<0.05,{ }^{*}, p<0.01,{ }^{* * *}, p<0.001$ compared with unstimulated control.

Figure 2: Metoprolol (MET) improved EPC functions under high glucose condition (HG) or from streptozotocin-induced diabetic mice (STZ). (A) Metoprolol enhanced the tube formation capacity of EPCs treated with high glucose $(33 \mathrm{mM})$ for $24 \mathrm{~h}$. (B) Metoprolol enhanced the migration capacity of EPCs treated with high glucose (33 mM) for $24 \mathrm{~h}$. (C) Metoprolol enhanced the tube formation capacity of EPCs from diabetic mice. (D) Metoprolol enhanced the migration capacity of EPCs from diabetic mice. (E) Metoprolol increased the number of circulating EPCs in diabetic mice. Scale bar: $50 \mu \mathrm{m} . \mathrm{n}=6$. Data represent mean \pm SEM. ${ }^{* *}, p<$ $0.01,{ }^{* * *}, p<0.001$ compared with unstimulated control. ${ }^{\#}, p<0.05,{ }^{\# \#}, p<0.001$ compared with HG group or STZ group.

Figure 3: Metoprolol (MET) decreased intracellular $\mathrm{O}_{2}^{-}$production and increased eNOS phosphorylation in EPCs. (A) High glucose (HG, $33 \mathrm{mmol} / \mathrm{L}$ ) treated EPCs were stain with DHE and assayed using flow cytometry.

(B) Intracellular $\mathrm{O}_{2}^{-}$production in EPCs from diabetic mice was measured by flow cytometry using DHE. (C)

Western blot analyses were performed to determine changes of phosphorylated and total eNOS expression in EPCs from STZ-induced diabetic mice with or without metoprolol treatment. $n=4-6$. Data represent mean \pm 
401 SEM. **, $p<0.01$ compared with unstimulated control. ${ }^{*}, p<0.05,{ }^{\#}, p<0.01$ compared with HG group or 402 STZ group.

403 Figure 4: Effects of five $\beta$-blockers on high-glucose induced reactive oxygen species (ROS) generation in

404

405

406

407

408

409

410

411

412

413

414

415

416

417

418

419

420

421

HUVECs. HUVECs were incubated with PRO (propranolol, $0.3 \mu \mathrm{M}$ ), ATE (atenolol, $3 \mu \mathrm{M}$ ), MET (metoprolol, $0.3 \mu \mathrm{M}$ ), BIS (bisoprolol, $0.3 \mu \mathrm{M}$ ), NEB (nebivolol, $3 \mathrm{nM}$ ), or control for $24 \mathrm{~h}$ and then stained with DHE (Dihydroethidium). HG (high glucose) group HUVECs were treated with 33mM D-glucose for $24 \mathrm{~h}$. Cells were read at $518 / 605 \mathrm{~nm}$ in a microplate reader and captured under the fluorescence microscope. Scale bar: $50 \mu \mathrm{m}$. $\mathrm{n}=6$. Data represent mean $\pm \mathrm{SEM} .{ }^{* * *}, p<0.001$ compared with unstimulated control. ${ }^{\#}, p<0.05,{ }^{\# \#}, p<0.001$ compared with HG group.

Figure 5: Metoprolol (MET) accelerated wound closure rates in STZ-induced diabetic mice (STZ). Wounds made with a $6 \mathrm{~mm}$ diameter biopsy punch were measured every 2 days until day 12. (A) Metoprolol improved the percentage of wound closure in STZ-induced diabetic mice compared with the untreated diabetic ones. (B) Representative photographs of the full thickness skin wounds. Mean \pm SEM. $\mathrm{n}=8 .{ }^{*} p<0.05$ vs. Control; ${ }^{*} p<$ 0.05 vs. STZ.

Figure 6: Metoprolol (MET) stimulated angiogenesis in STZ-induced diabetic mice. Biopsies were taken for immunohistology with CD31 mAb to detect blood vessels in the wound region (black arrows). Scale bar: $50 \mu \mathrm{m}$. Mean \pm SEM. $(* p<0.05, * * p<0.01 ; \mathrm{n}=5$ per group $)$

Figure 7: Effect of metoprolol on endothelial function. (A) Vascular endothelial function was evaluated by reactive hyperemia-peripheral arterial tonometry (RH-PAT) index in type 2 diabetes patients treated with bisoprolol or metoprolol. (B) Representative signals of RH-PAT in control or diabetic subjects. Normal response characterized by a distinct increase in the signal amplitude after cuff release compared with baseline. $(* p<0.05$, 
$422 \quad * * p<0.01)$ 


\section{Figure 1}

Effects of five $\beta$-blockers on HUVECs and EPCs tube formation and migration

HUVECS or EPCs were incubated with PRO (propranolol, $0.3 \mu \mathrm{M}$ ), ATE (atenolol, $3 \mu \mathrm{M}$ ), MET (metoprolol, $0.3 \mu \mathrm{M}$ ), BIS (bisoprolol, $0.3 \mu \mathrm{M}$ ), NEB (nebivolol, $3 \mathrm{nM}$ ), or control for 24 hours and then tested. (A) Typical HUVECs tube formation and migration. (B) Quantitative evaluation of the tube numbers and ther numbers of migrated HUVECs from (A). (C) Quantitative evaluation of the tube numbers and the numbers of migrated EPCs. Scale bar: $50 \mu \mathrm{m} . \mathrm{n}=6$. Data represent mean \pm SEM. $*, p<0.05, * *, p<0.01, * * *, p<0.001$ compared with unstimulated control. 

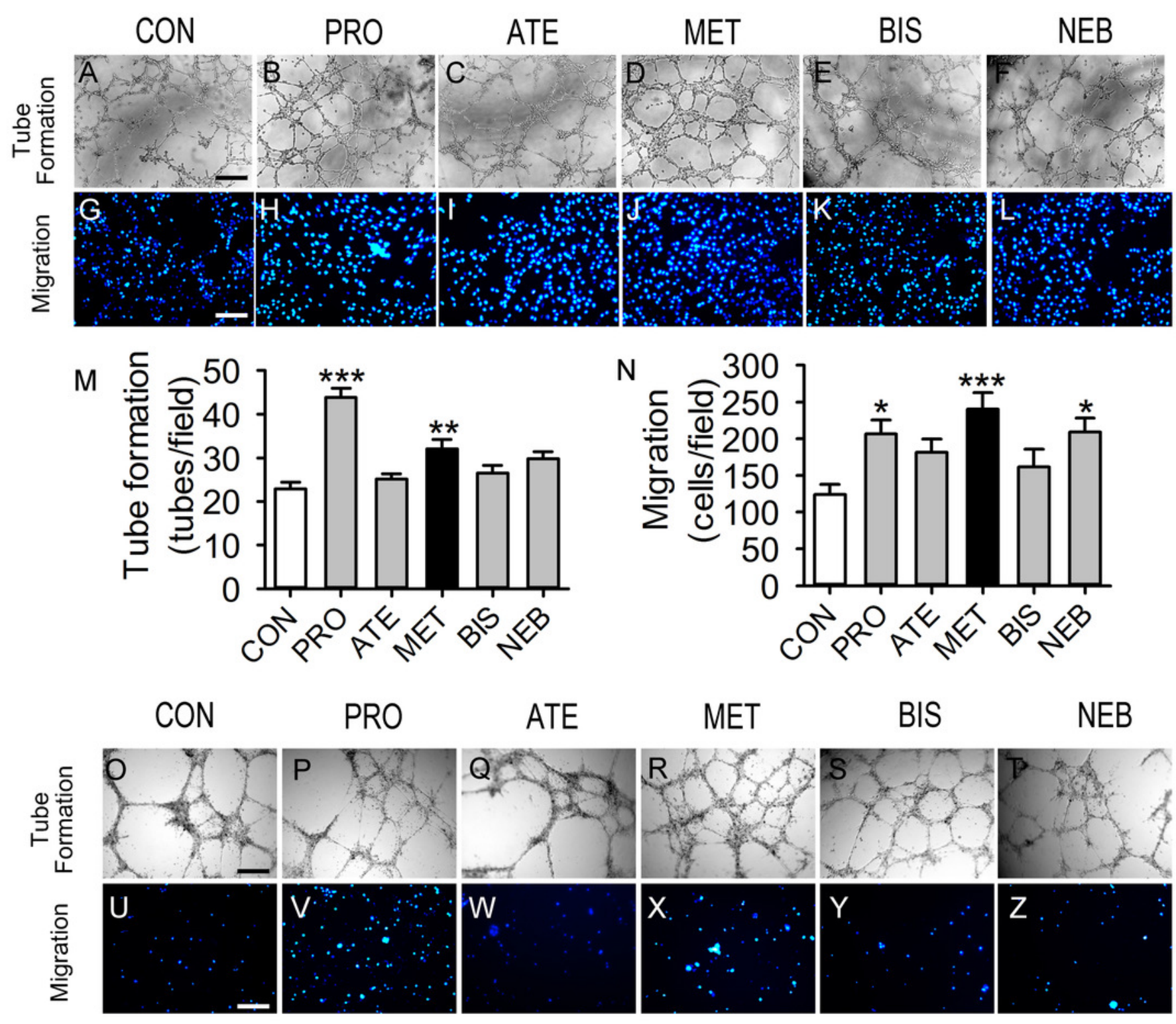

MET BIS

NEB
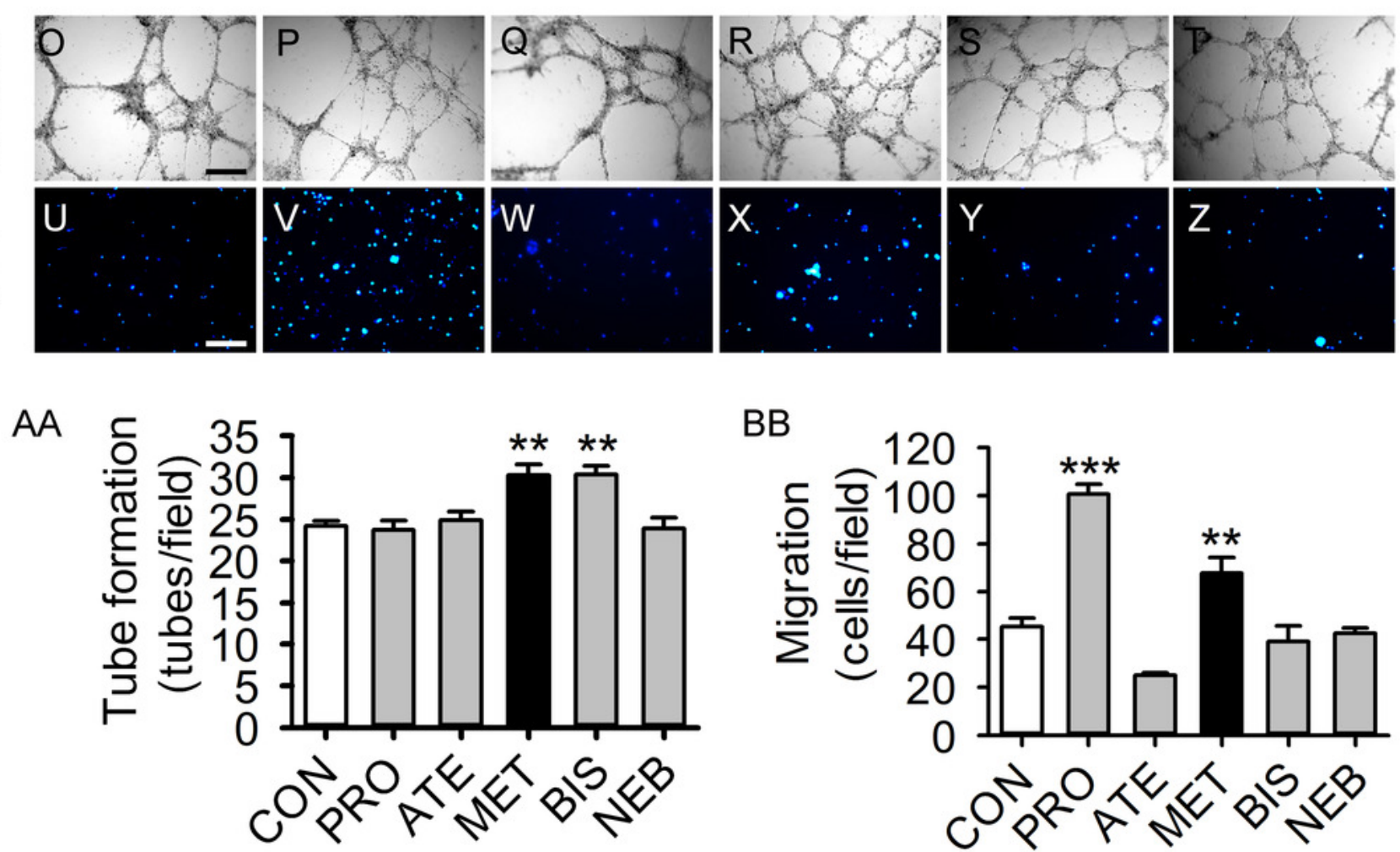

BB

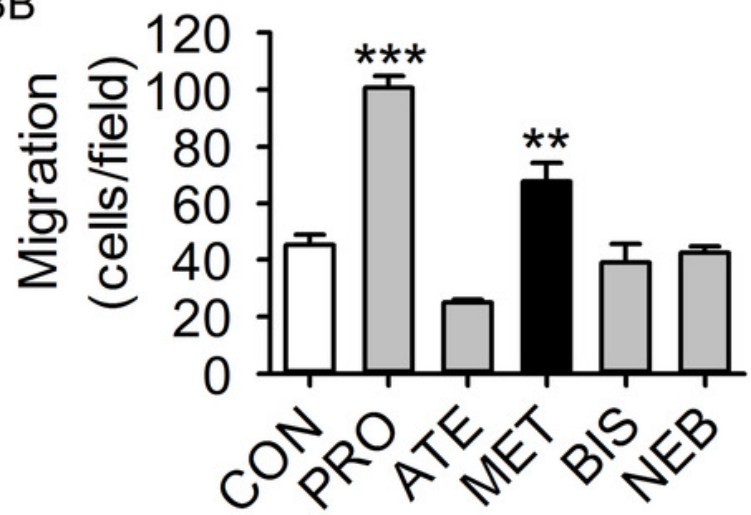




\section{Figure 2}

Metoprolol (MET) improved EPC functions under high glucose condition (HG) or from streptozotocin-induced diabetic mice (STZ).

(A) Metoprolol enhanced the tube formation capacity of EPCs treated with high glucose (33 $\mathrm{mM}$ ) for $24 \mathrm{~h}$. (B) Metoprolol enhanced the migration capacity of EPCs treated with high glucose (33 mM) for $24 \mathrm{~h}$. (C) Metoprolol enhanced the tube formation capacity of EPCs from diabetic mice. (D) Metoprolol enhanced the migration capacity of EPCs from diabetic mice. (E) Metoprolol increased the number of circulating EPCs in diabetic mice. Scale bar: $50 \mu \mathrm{m} . \mathrm{n}$ $=6$. Data represent mean \pm SEM. $* *, p<0.01,{ }^{* * *}, p<0.001$ compared with unstimulated control. ${ }^{\#}, p<0.05,{ }^{\# \#}, p<0.001$ compared with HG group or STZ group. 

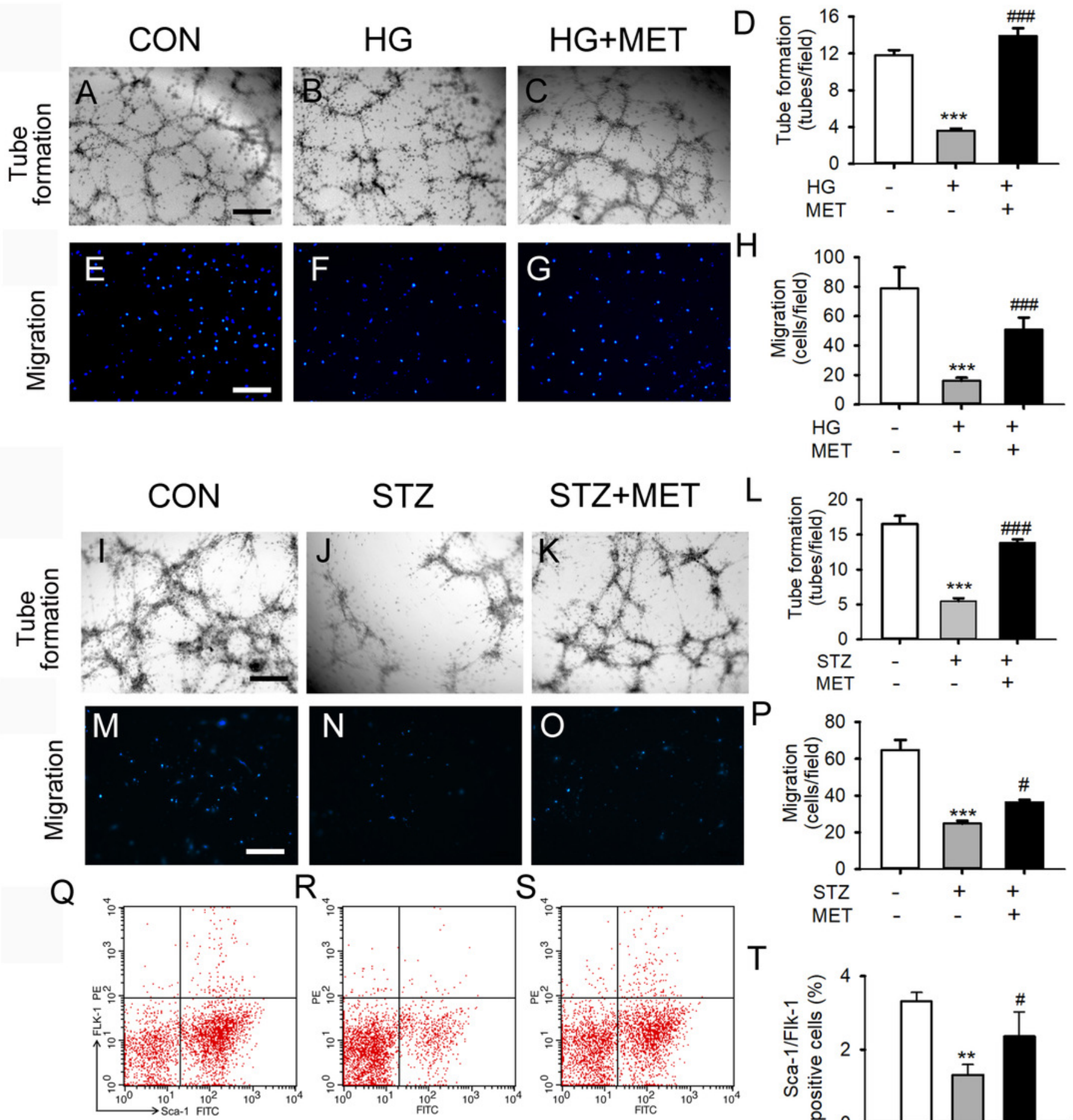

$\mathrm{T}$

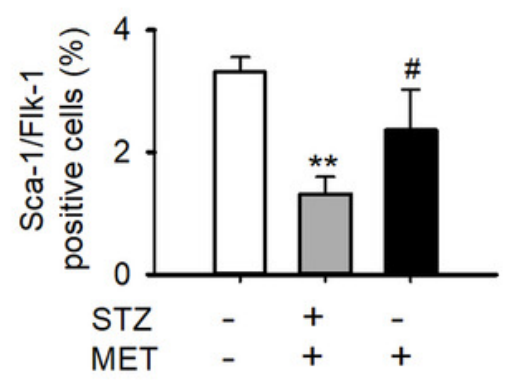




\section{Figure 3}

Metoprolol (MET) decreased intracellular $\mathrm{O}_{2}^{-}$production and increased eNOS phosphorylation in EPCs.

(A) High glucose (HG, $33 \mathrm{mmol} / \mathrm{L})$ treated EPCs were stain with DHE and assayed using flow cytometry. (B) Intracellular $\mathrm{O}_{2}$ production in EPCs from diabetic mice was measured by flow cytometry using DHE. (C) Western blot analyses were performed to determine changes of phosphorylated and total eNOS expression in EPCS from STZ-induced diabetic mice with or without metoprolol treatment. $\mathrm{n}=4-6$. Data represent mean $\pm \mathrm{SEM}$. $* *, p<0.01$ compared with unstimulated control. ${ }^{*}, p<0.05,{ }^{\#}, p<0.01$ compared with HG group or STZ group. 

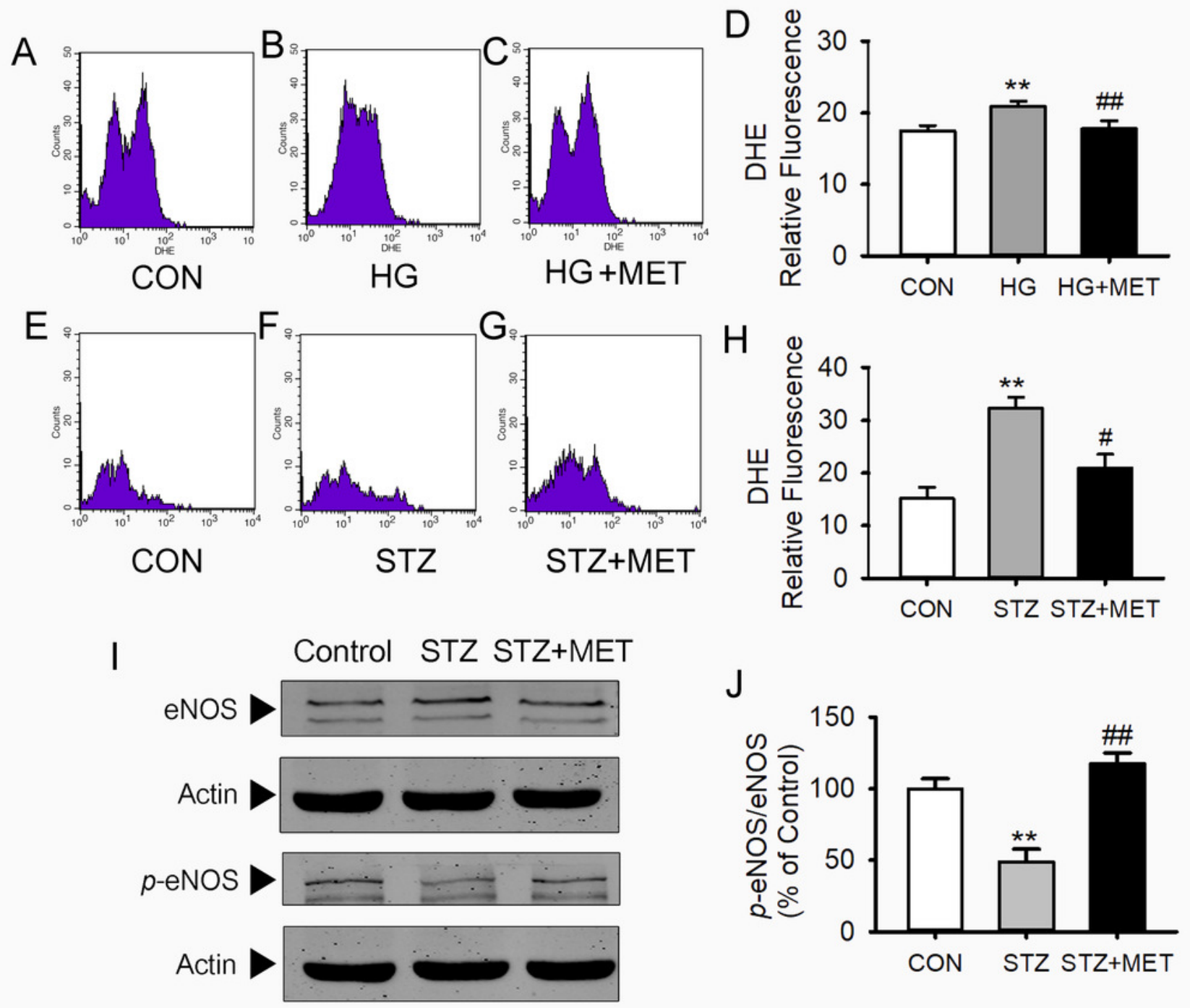


\section{Figure 4}

Effects of five $\beta$-blockers on high-glucose induced reactive oxygen species (ROS) generation in HUVECs.

HUVECs were incubated with PRO (propranolol, $0.3 \mu \mathrm{M}$ ), ATE (atenolol, $3 \mu \mathrm{M}$ ), MET (metoprolol, $0.3 \mu \mathrm{M}$ ), BIS (bisoprolol, $0.3 \mu \mathrm{M}$ ), NEB (nebivolol, $3 \mathrm{nM}$ ), or control for $24 \mathrm{~h}$ and then stained with DHE (Dihydroethidium). HG (high glucose) group HUVECs were treated with $33 \mathrm{mM}$ D-glucose for $24 \mathrm{~h}$. Cells were read at $518 / 605 \mathrm{~nm}$ in a microplate reader and captured under the fluorescence microscope. Scale bar: $50 \mu \mathrm{m} . \mathrm{n}=6$. Data represent mean \pm SEM. ***, $p<0.001$ compared with unstimulated control. ${ }^{*}, p<0.05,{ }^{\# \# *}, p<0.001$ compared with HG group. 

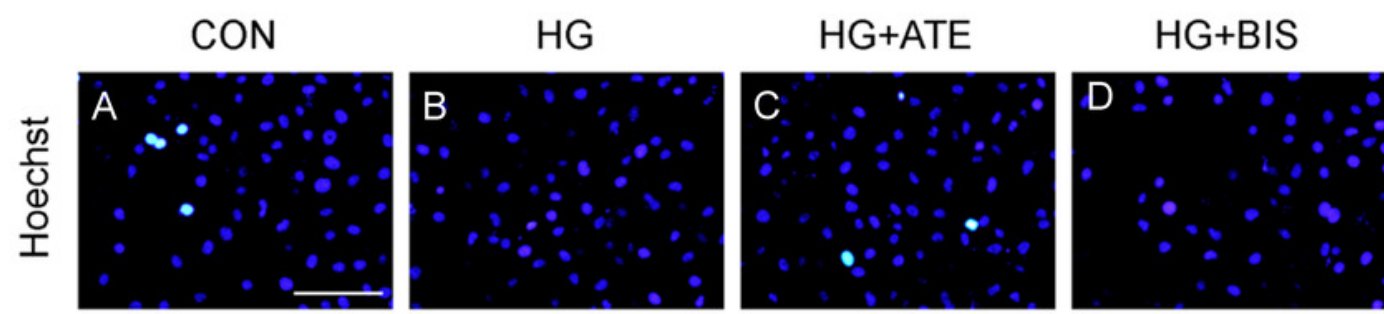

\section{HG+MET}
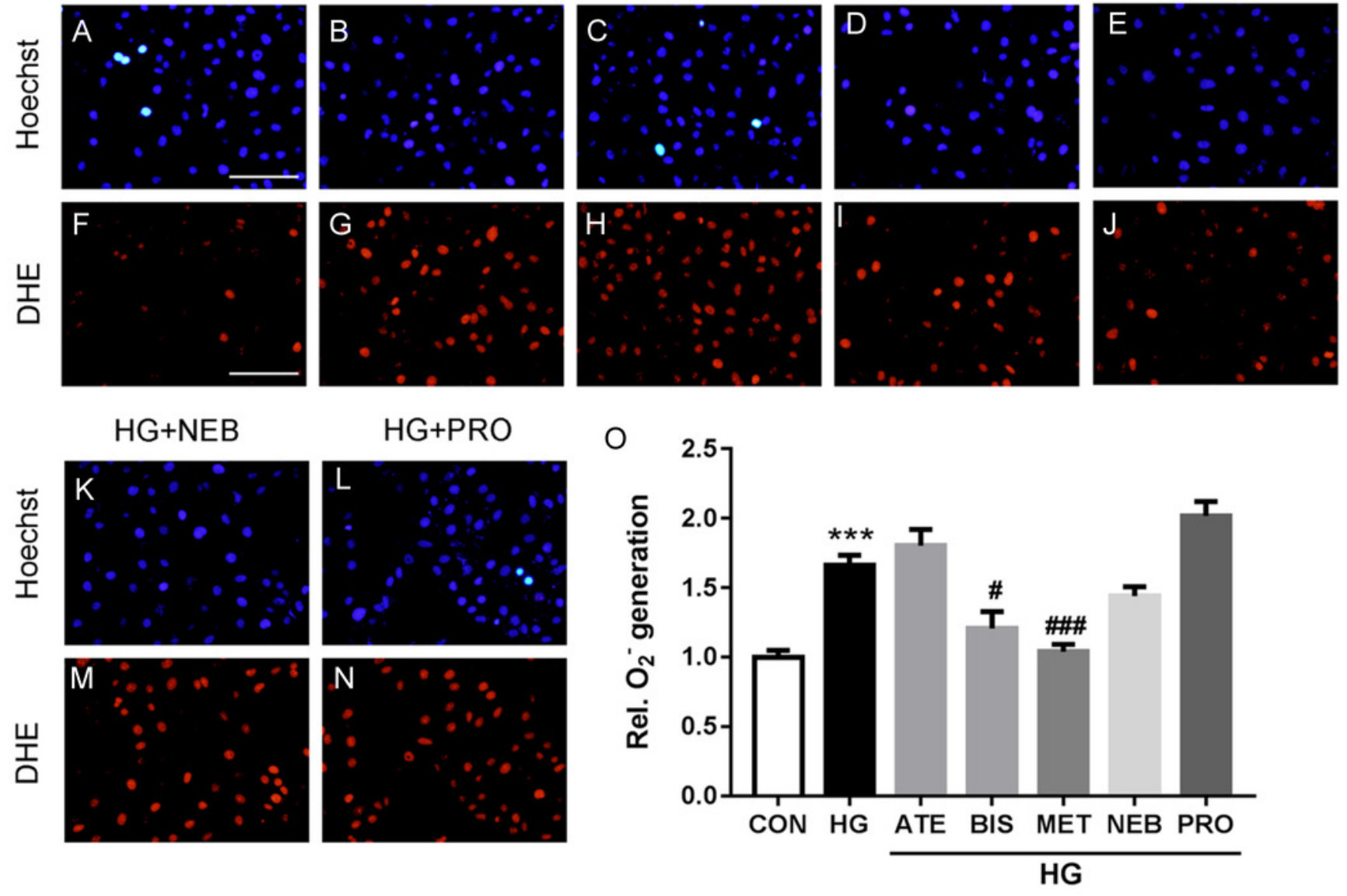


\section{Figure 5}

Metoprolol (MET) accelerated wound closure rates in STZ-induced diabetic mice (STZ).

Wounds made with a $6 \mathrm{~mm}$ diameter biopsy punch were measured every 2 days until day 12 .

(A) Metoprolol improved the percentage of wound closure in STZ-induced diabetic mice compared with the untreated diabetic ones. (B) Representative photographs of the full thickness skin wounds. Mean \pm SEM. $n=8 .{ }^{*} p<0.05$ vs. Control; ${ }^{*} p<0.05$ vs. STZ. 
A
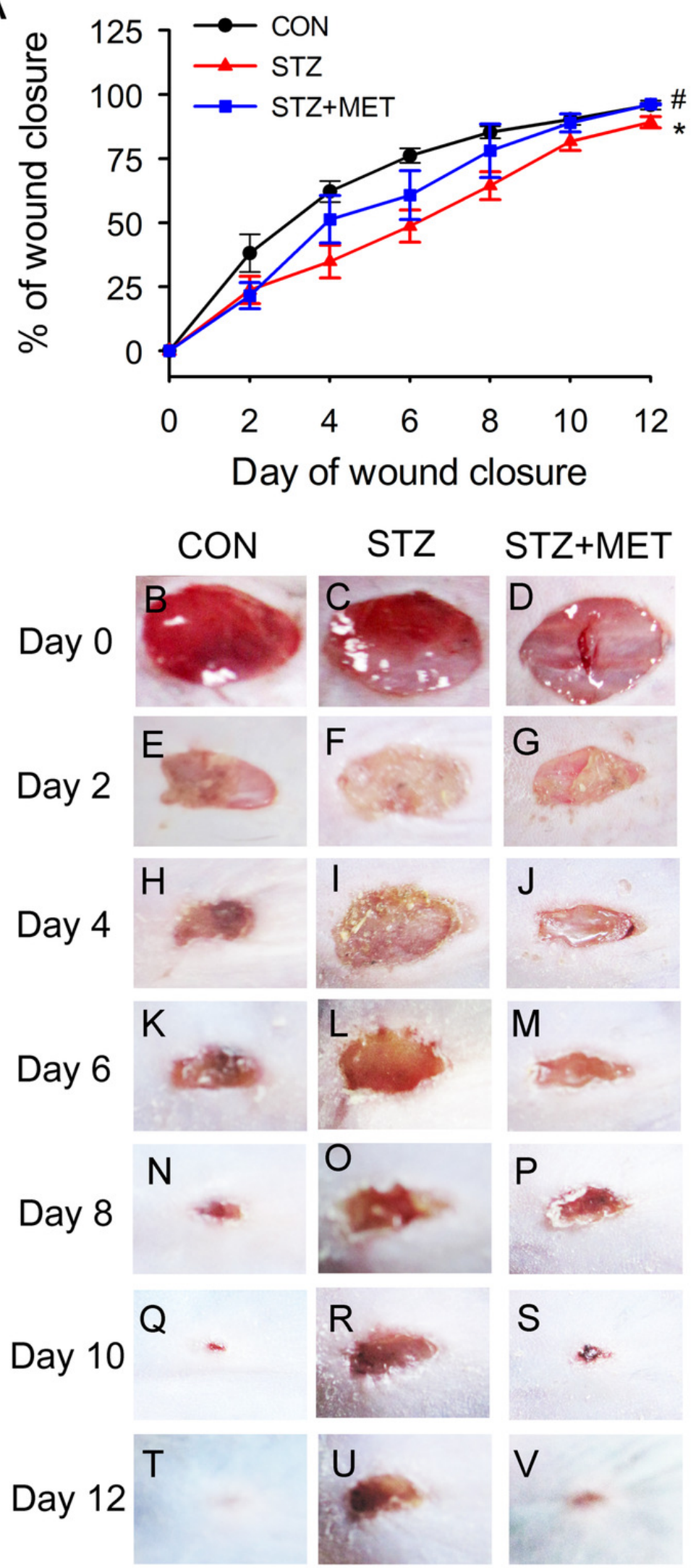
Figure 6

Metoprolol (MET) stimulated angiogenesis in STZ-induced diabetic mice.

Biopsies were taken for immunohistology with CD31 mAb to detect blood vessels in the wound region (black arrows). Scale bar: $50 \mu \mathrm{m}$. Mean \pm SEM. $(* p<0.05, * * p<0.01 ; \mathrm{n}=5$ per group) 

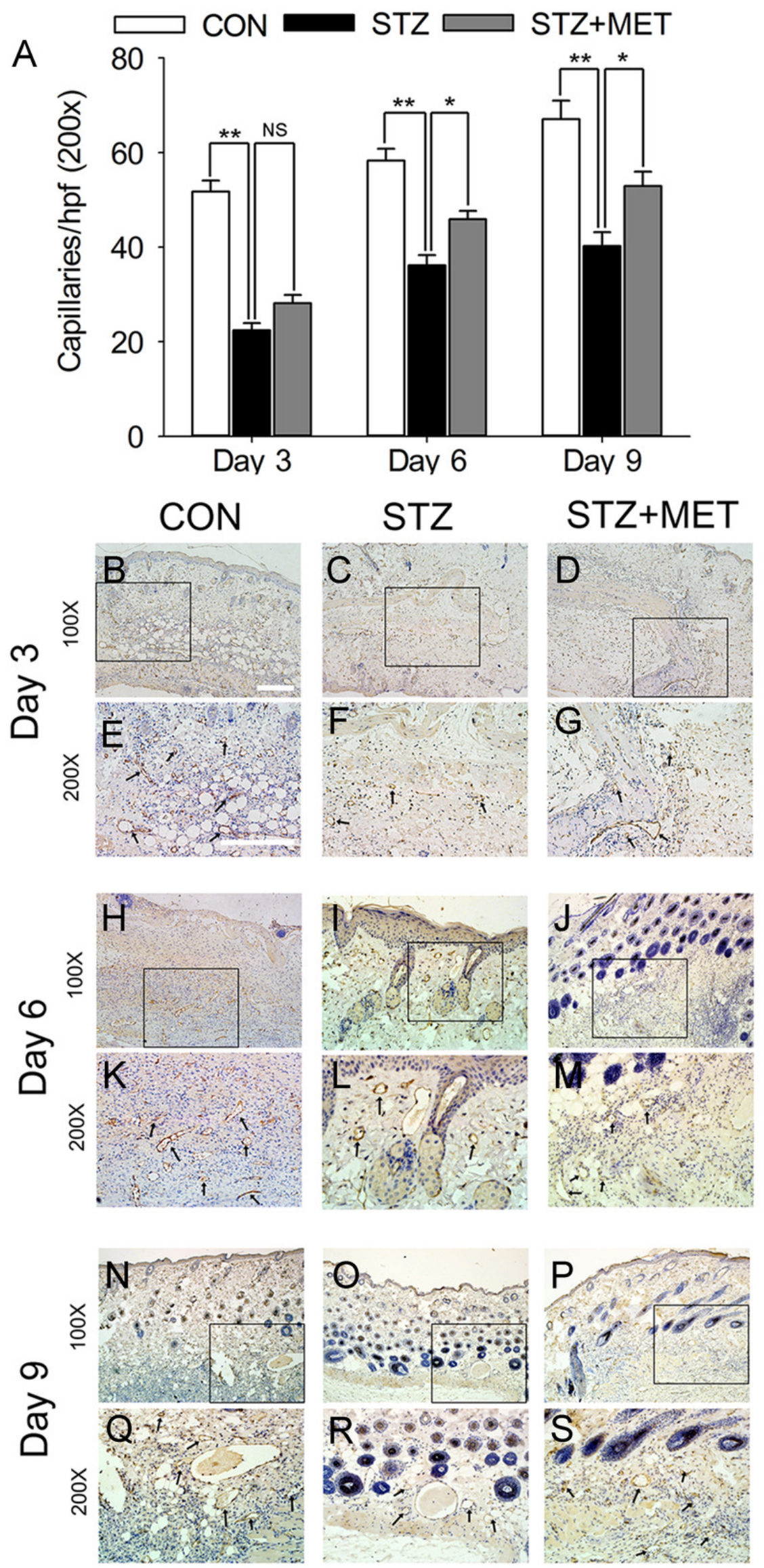


\section{Figure 7}

Effect of metoprolol on endothelial function.

(A) Vascular endothelial function was evaluated by reactive hyperemia-peripheral arterial tonometry (RH-PAT) index in type 2 diabetes patients treated with bisoprolol or metoprolol. (B) Representative signals of RH-PAT in control or diabetic subjects. Normal response characterized by a distinct increase in the signal amplitude after cuff release compared with baseline. $(* p<0.05, * * p<0.01)$ 
A

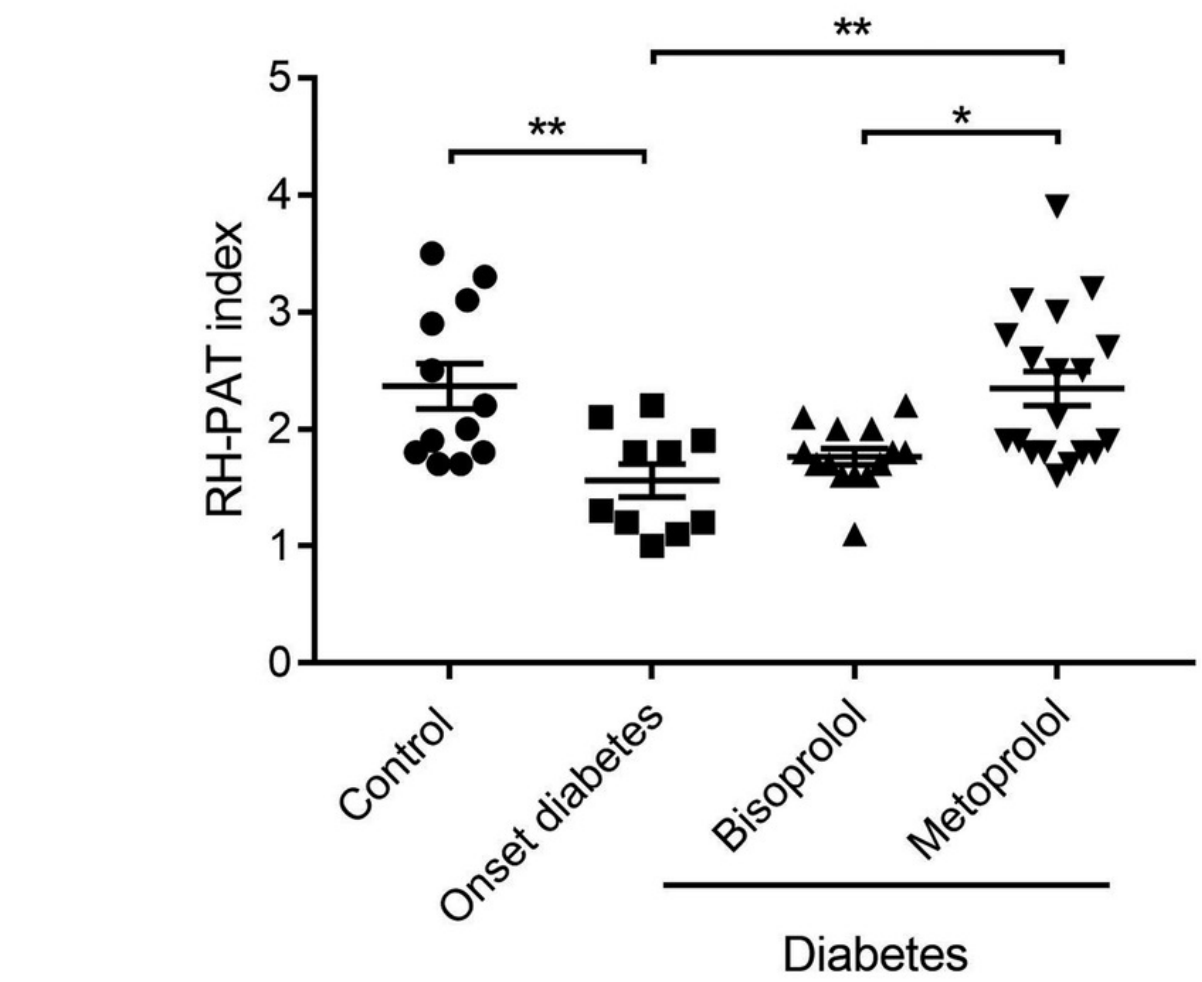

B

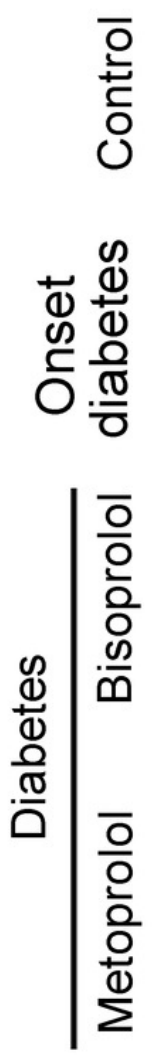

Hyperemic

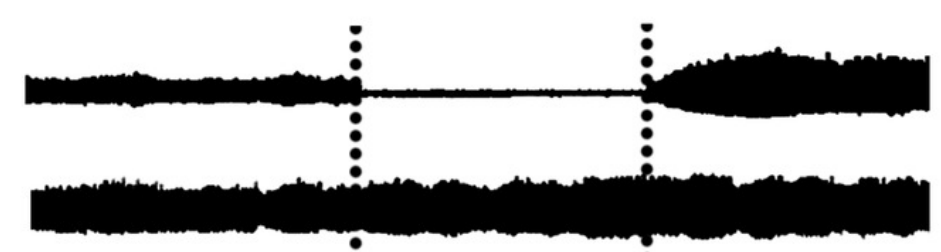

Control finger

Hyperemic finger

Control finger

Hyperemic finger

Control finger

Hyperemic finger

Control finger
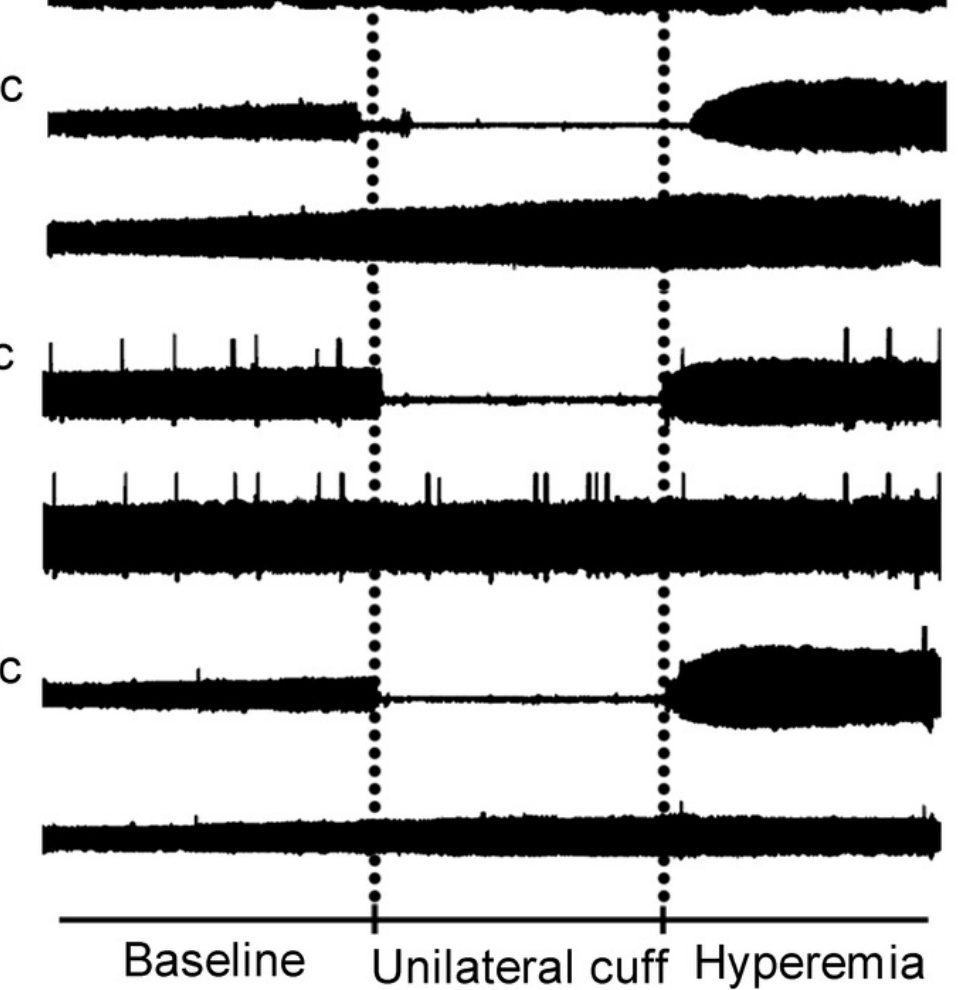

5 min occlusion 


\section{Table 1 (on next page)}

Baseline Characteristics of the patients.

Baseline Characteristics of the patients. 


\begin{tabular}{|c|c|c|c|c|}
\hline \multirow{2}{*}{ Characteristic } & \multirow{2}{*}{$\begin{array}{l}\text { Control } \\
\text { subjects }\end{array}$} & \multirow{2}{*}{$\begin{array}{c}\text { Onset diabetic } \\
\text { patients }\end{array}$} & \multicolumn{2}{|c|}{ Type 2 diabetic patients } \\
\hline & & & Bisoprolol & Metoprolol \\
\hline$n$ & 12 & 10 & 14 & 19 \\
\hline Age (years) & $49 \pm 7.5$ & $53 \pm 7.6$ & $53 \pm 12.3$ & $66 \pm 10.6$ \\
\hline Sex (male) & 6 & 5 & 7 & 9 \\
\hline $\operatorname{BMI}\left(\mathrm{Kg} / \mathrm{m}^{2}\right)$ & $22 \pm 1.3$ & $26 \pm 4.5$ & $28 \pm 4.7^{*}$ & $25 \pm 2.9^{*}$ \\
\hline HbA1c (\%) & $5.9 \pm 0.09$ & $6.9 \pm 0.46^{*}$ & $6.9 \pm 0.50^{*}$ & $7.2 \pm 0.38^{*}$ \\
\hline $\mathrm{TC}(\mathrm{mmol} / \mathrm{L})$ & $4.3 \pm 0.22$ & $3.9 \pm 0.36$ & $4.1 \pm 0.46$ & $4.5 \pm 0.27$ \\
\hline TG (mmol/L) & $1.7 \pm 0.24$ & $1.6 \pm 0.24$ & $1.4 \pm 0.23$ & $1.9 \pm 0.32$ \\
\hline HDL-C (mmol/L) & $1.2 \pm 0.09$ & $1.4 \pm 0.18$ & $1.3 \pm 0.08$ & $1.1 \pm 0.06$ \\
\hline LDL-C (mmol/L) & $2.4 \pm 0.15$ & $2.4 \pm 0.14$ & $2.5 \pm 0.18$ & $2.4 \pm 0.18$ \\
\hline \multicolumn{5}{|l|}{ Cardiovascular risk factors } \\
\hline Arterial hypertension & 0 & 10 & 14 & 19 \\
\hline Hyperlipidemia & 0 & 0 & 4 & 14 \\
\hline Smoking & 0 & 4 & 1 & 2 \\
\hline \multicolumn{5}{|l|}{ Medical history } \\
\hline Myocardial infarction & 0 & 0 & 3 & 12 \\
\hline Stroke & 0 & 0 & 2 & 5 \\
\hline \multicolumn{5}{|l|}{ Medications } \\
\hline $\begin{array}{l}\text { ACE inhibitor or } \mathrm{AT}_{2^{-}} \\
\text {blocker }\end{array}$ & 0 & 0 & 7 & 12 \\
\hline Calcium-channel & 0 & 0 & 6 & 7 \\
\hline \multicolumn{5}{|l|}{ blockers } \\
\hline Diuretics & 0 & 0 & 0 & 2 \\
\hline Antiplatelet agents & 0 & 0 & 3 & 10 \\
\hline Metformin & 0 & 0 & 1 & 5 \\
\hline Sulfonylureas & 0 & 0 & 3 & 5 \\
\hline Insulin & 0 & 0 & 0 & 2 \\
\hline
\end{tabular}

Data are means $\pm \mathrm{SD}$ or $n,{ }^{*} p<0.05 v s$. Control subjects. 